\title{
DEMOCRACIA E LEGITIMACÃO: UMA ANÁLISE A PARTIR DA POLÍTICA PROCEDIMENTALISTA DE JÜRGEN HABERMAS
}

\author{
DEMOCRACY AND LEGITIMATION: AN ANALYSIS BASED ON POLICY PROCEDURALIST JURGEN \\ HABERMAS
}

\author{
DEMOCRACIA Y LEGITIMACIÓN: UN ANÁLISIS A PARTIR DE LA POLÍTICA PROCEDIMENTALISTA \\ DE JÜRGEN HABERMAS
}

Luiz Henrique Urquhart Cademartori ${ }^{1}$

Grazielly Alessandra Baggenstoss²

\section{RESUMO}

\begin{abstract}
Jürgen Habermas, como expoente da segunda geração da Escola de Frankfurt, propôs-se a explicar as interações humanas dentro de seu bojo social, por meio do interesse no consenso, resgatando os elementos referenciais que constituem a verdade compartilhada entre os sujeitos em um diálogo. Considerando que os processos de coisificação são resultado de uma integração repressiva, imposta pela economia oligopolista e por um aparato estatal autoritário, o autor estudado, contando com o trilhar da experiência histórica das verdades compartilhadas e dos modos de articulação do poder dentro da sociedade, estabelece a teoria da política deliberativa, uma concepção procedimentalista da democracia, surgida com a união de determinados elementos das concepções democráticas liberal e republicana, como uma forma de propor a legitimidade das instituições de poder existentes na sociedade atual, já que seriam criadas a partir da comunicação. Essa comunicação propiciaria uma relação intersubjetiva capaz de encaminhar os indivíduos e a sociedade à emancipação.
\end{abstract}

PALAVRAS-CHAVE: Jürgen Habermas. Política Procedimentalista. Democracia Deliberativa.

\section{ABSTRACT}

Jürgen Habermas, as an exponent of the second generation of the Frankfurt School, sought to explain the human interactions at their social core, by means of interest in the consensus, making use of the referential elements that constitute truth shared between the individuals in a dialogue. Whereas the processes of objectification are the result of an integration of repression imposed by the oligopolistic economy and an authoritarian state apparatus, the author, taking advantage of historical experience of shared truths and modes of power articulation in society, establishes the theory of deliberative politics, a proceduralist

1 Pós-doutorado pela Universidade de Granada (Espanha). Doutor e Mestre pela Universidade Federal de Santa Catarina Professor titular dos cursos de Graduação e Pós-Graduação em Direito, stricto sensu da Universidade Federal de Santa Catarina (UFSC).

2 Doutoranda em Direito, Política e Sociedade, pelo Programa de Doutorado da Pós Graduação em Ciências Jurídicas da Universidade Federal de Santa Catarina (UFSC), com Linha de Pesquisa em Constituição e Direitos Humanos; Mestra em Direito, Estado e Sociedade, pelo Programa de Mestrado da Pós Graduação em Ciências Jurídicas da Universidade Federal de Santa Catarina (UFSC); Pesquisadora do Projeto de Consolidação das Leis Catarinenses, instituído pela Universidade Federal de Santa Catarina (UFSC) e Assembleia Legislativa do Estado de Santa Catarina (ALESC); Consultora Colaboradora da Fundação Escola de Governo do Estado de Santa Catarina (ENA/SC); Assessora Jurídica da $1^{\text {a }}$ Vara Criminal da Comarca de São José (TJSC).E-mail: grazyab@gmail.com 
concept of democracy that emerged out of the union of some elements of liberal democratic and republican concepts, as a form of proposing the legitimacy of existing institutions of power in society today, since these would be created based on communication. Such communication would provide an intersubjective relationship capable of directing individuals and society to emancipation.

KEYWORDS:]ürgen Habermas. Proceduralist Politics. Deliberative Democracy.

\section{RESUMEN}

Jürgen Habermas, como exponente de la segunda generación de la Escuela de Frankfurt, se propuso explicar las interacciones humanas dentro de su meollo social, por medio del interés en el consenso, rescatando los elementos referenciales que constituyen la verdad compartida entre los sujetos en un diálogo. Considerando que los procesos de cosificación son resultado de una integración represiva impuesta por la economía oligopólica y por un aparato estatal autoritario, el autor estudiado, contando con la experiencia histórica de las verdades compartidas y de los modos de articulación del poder dentro de la sociedad, establece la teoría de la política deliberativa, una concepción procedimentalista de la democracia, surgida con la unión de determinados elementos de las concepciones democráticas liberal y republicana, como una forma de proponer la legitimidad de las instituciones de poder existentes en la sociedad actual, ya que serían creadas a partir de la comunicación. Esa comunicación propiciaría una relación intersubjetiva capaz de encaminar a los individuos y a la sociedad hacia la emancipación.

PALABRAS CLAVE: Jürgen Habermas. Política Procedimentalista. Democracia Deliberativa.

\section{INTRODUÇÃO}

No início de seus estudos e antes de elaborar a proposta da política procedimentalista, Jürgen Habermas dedicou-se à crítica à ideologia, à hermenêutica, à pragmática e, finalmente, sediou-se no direito e na ética ${ }^{3}$.

A produção científica habermasiana, por esse motivo, além de extensa, é complexa e profunda, porque $\mathrm{o}$ autor não abandonou as pesquisas anteriores em detrimento das seguintes, mas as acoplou de modo a consubstanciar um grande sistema teórico que expusesse noções satisfatórias sobre, especialmente, o mundo político e social. Isso com o fito de entender e questionar a alienação do subsistema sociocultural e emancipá-lo, atingindo, assim, a evolução da sociedade e, por consequência, do próprio ser humano.

Partiu Jürgen Habermas, nesse intento, de definições advindas de suas pesquisas acerca das instituições integrantes do Estado, da sociedade civil e da própria realidade.

\section{A SOCIEDADE CIVIL COMO SISTEMA INTEGRADOR DOS PLANOS SUBSISTEMÁTICOS SOCIOCULTURAL, ECONÔMICO E POLÍTICO}

Segundo o autor, então, as sociedades civis atuais podem ser definidas como um conjunto sistemático hipercomplexo, que apresenta constantes alterações em seus elementos sistêmicos e/ou nos valores-meta ("em que estão interligadas as definições culturais de vida social e os imperativos da sobrevivência que podem ser reconstruídos em teorias de sistema"4), com o objetivo de que

3 BORGES, Bento Itamar; GOMES, Luiz Roberto; JESUS, Osvaldo Freitas (Org.). Direito e democracia em Habermas: pressupostos e temas em debate. São Paulo: Xamã, 2010. p. 60.

4 Os valores-meta dos sistemas sociais são produtos, de um lado, dos valores culturais da tradição constitutiva e, do outro lado, dos requisitos não normativos da integração sistêmica. HABERMAS, Jürgen. A crise de legitimação no capitalismo tardio. 2. ed. Rio de Janeiro: Edições Tempo Brasileiro, 2002. p. 18-19. 
sejam mantidos em um nível de controle flexível à faticidade ${ }^{5}$. Para tanto, a margem de tolerância do sistema, dentro da qual os valores-meta podem variar sem pôr em perigo crítico sua existência contínua ou sem perder sua identidade, deve ser mantida por meio do respeito às estruturas normativas do sistema, quais sejam, as que permitem a sua identidade. Assim, mantêm-se a coesão e a adequação de seus subsistemas ao conjunto sistêmico.

A complexidade das sociedades atuais engloba, básica e analiticamente, os seguintes subsistemas: o subsistema sociocultural, o subsistema político e o subsistema econômico. O subsistema sociocultural possui, como estruturas normativas, sistemas de status e formas subculturais de vida e apresenta distribuição de recompensas disponíveis privadamente e direitos de dispor. O subsistema político, por sua vez, apresenta as estruturas normativas, que são as instituições políticas do Estado e as categorias de substrato, que são a distribuição do poder legítimo, respectiva força estrutural e racionalidade organizacional disponível. Por fim, o subsistema econômico tem as instituições econômicas (problemas de produção), como as estruturas normativas, a distribuição de poder econômico, a força estrutural e as forças disponíveis de produção6.

Nesse esquema da sociedade complexa7, "o sistema político, enquanto centro de controle separado, assume uma condição subordinante diante de sistemas socioculturais e econômicos" Contudo o subsistema político distanciou-se do subsistema sociocultural com o advento de uma esfera livre do Estado, a partir do Estado de Direito e a política liberal, e aproximou-se do subsistema econômico.

Não obstante a separação entre o social e o político e a aproximação entre este e o econômico, o subsistema de mercado permanecia dependente da oferta de legitimação do subsistema sociocultural. Apenas uma relativa desconexão do sistema econômico perante o político é capaz de instalar uma esfera emergida da sociedade burguesa que seja livre dos laços socioculturais e transferir a legitimação para as orientações de ação estratégica utilitária dos participantes do mercado. Com esse escopo, portanto, "empresários competidores então tomam suas decisões de acordo com níveis de competição orientada ao lucro e substituem a ação orientada por valores por ações guiadas por interesses" .

Com o Estado Democrático de Direito e a solidificação do capitalismo, sobrevém a anonimização política da dominação de classe, que acarreta não só a libertação do sistema econômico em relação ao sistema político (com as legitimações de subsistemas integrativos socialmente), mas a sua capacitação ao longo das suas tarefas integrativas sistêmicas, de trazer uma contribuição para a integração social ${ }^{10}$. Assim, o sistema social torna-se sensivelmente suscetível ao sistema econômico, e os problemas de condução do sistema social tornam-se ameaçadores de identidade.

No plano estratégico de substituição de valores por interesse, é empregado o método científico que, além de ser bem-sucedido na dominação da natureza, proporciona êxito, igualmente, na apresentação de instrumentos de dominação eficientes do homem entre os homens. Denuncia Jürgen Habermas que:

Hoje, a dominação eterniza-se e amplia-se não só mediante a tecnologia, mas como tecnologia; e esta proporciona a grande legitimação ao poder político expansivo, que assume a si todas as esferas da cultura. Neste universo, a tecnologia proporciona igualmente a grande racionalização da falta de liberdade do homem e demonstra a impossibilidade técnica de ser autônomo, de determinar pessoalmente a sua vida ${ }^{11}$

E tal falta de liberdade não é irracional ou política, mas é resultado da sujeição do ser humano ao aparelho técnico que amplia a comodidade da vida e intensifica a produtividade do trabalho. "A racionalidade tecnológica protege, assim, antes a legalidade da dominação em vez de a eliminar, e o horizonte instrumentalista da razão abre-se a uma sociedade totalitária de base racional"12.

5 HABERMAS, Jürgen. A crise de legitimação no capitalismo tardio. p. 18.

6 HABERMAS, Jürgen. A crise de legitimação no capitalismo tardio. p. 18.

7 Como sistema que apresenta estruturas normativas dentro de sua linguagem, em que cada sistema social é definido segundo o ponto de vista de seu centro de controle.

8 HABERMAS, Jürgen. A crise de legitimação no capitalismo tardio. p. 16.

9 HABERMAS, Jürgen. A crise de legitimação no capitalismo tardio. p. 35.

10 HABERMAS, Jürgen. A crise de legitimação no capitalismo tardio. p. 37.

11 HABERMAS, Jürgen. Tecnologia e ciência como "ideologia". Lisboa: Edições 70, 2009. p. 49.

12 HABERMAS, Jürgen. Tecnologia e ciência como "ideologia". p. 49. 
Portanto, com a independência do subsistema econômico, o que antes representava a condução social por meio da dominação política do poder social, que estava imediatamente na base da relação entre capitalistas e assalariados ${ }^{13}$, hoje, com a dominação apolítica de classe, legitima a despolitização das massas pela consciência tecnocrática, que é a ideologia estruturada por privilégios de oportunidades imediatas da vida, acessíveis por intermédio do progresso técnico-científico ${ }^{14}$.

Diante de tal estrutura sistêmica, segundo o autor:

[...] a lealdade das massas só pode obter-se por meio de compensações destinadas à satisfação de necessidades privatizadas. A interpretação das realizações pelas quais se justifica o sistema não pode, em princípio, ser política: refere-se imediatamente a distribuições neutras quanto à sua aplicação de dinheiro e tempo livre e, mediatamente, à justificação tecnocrática da exclusão das questões práticas. Por isso, a nova ideologia distingue-se das antigas pelo facto de separar os critérios de justificação da organização da convivência, portanto, das regulações normativas da interacção em geral e, nesse sentido, os despolitizar e, em vez disso, os vincular às funções de um suposto sistema de acção racional dirigida a fins ${ }^{15}$.

Assim, dentro do domínio público estruturalmente despolitizado, a legitimação é sintetizada por dois fatores: o privatismo cívico, ou seja, "abstinência política combinada a uma orientação para a carreira, o lazer e o consumo, que promove a expectativa de adequadas recompensas dentro do sistema (dinheiro, lazer e segurança)"16; e a justificação da própria despolitização estrutural, fornecida pelas "teorias de elite democrática (que remonta a Schumpeter e Max Weber) e por teorias sistêmicas tecnocráticas (que remontam ao institucionalismo da década de 20)"17.

Se houvesse, nas sociedades complexas ocidentais, uma participação efetiva dos cidadãos nos processos de formação de vontade política (a democracia substantiva), tornar-se-ia possível a conscientização dos membros sociais acerca das contradições entre a produção socializada administrativamente, a contínua apropriação privada e o uso privado da mais valia ${ }^{18}$.

No entanto, para proteger a fachada distributiva compensadora, a dominação política no capitalismo de regulação estatal incorporou estruturas pseudolegitimantes na sociedade para prevenir os perigos que ameaçam o sistema ${ }^{19}$.

Assim, com o fito de manter esta contradição longe de ser objeto de discussão, o aparato administrativo do subsistema político formata-se de modo suficientemente independente da formação da vontade legitimante. Segundo Habermas:

A montagem das instituições formais democráticas em seus processos permite divisões administrativas a serem feitas largamente independente de motivações específicas dos cidadãos. Isto ocorre através de um processo de legitimação que elide motivações generalizadas, isto é, difunde a lealdade das massas, mas evita participação. [...] gera instituições e processos que são democráticos na forma, enquanto a cidadania, no meio de uma sociedade politicamente objetiva, goza do status de cidadãos passivos, apenas com direito de embargar a aclamação. As decisões privadas autônomas de investimentos têm, pois, sua necessária complementação no privatismo cívico da sociedade civil${ }^{20}$.

Além de a despolitização das massas legitimar a consciência tecnocrática e o abstencionismo cívico, ela também causa "uma autoprojecção dos homens em categorias [...]: os modelos coisificados das ciências transmigram para um mundo sociocultural da vida e obtêm ali um poder objectivo sobre a autocompreensão"21, em que os indivíduos, motivados pelos benefícios e pela satisfação de interesses advindos das técnicas estratégicas e instrumentais, abandonam os meios comunicativos de obtenção de recompensas pela interação social e pela linguagem.

13 HABERMAS, Jürgen. Tecnologia e ciência como "ideologia". p. 81.

14 HABERMAS, Jürgen. Tecnologia e ciência como "ideologia". p. 78-81, passim.

15 HABERMAS, Jürgen. Tecnologia e ciência como "ideologia". p. 81.

16 Segundo o autor, "esse privatismo é levado em consideração por programas substitutivos do Estado previdenciário, que também incorpora elementos de uma ideologia de realização transferida para o sistema educacional." HABERMAS, Jürgen. Tecnologia e ciência como "ideologia". p. 52.

17 HABERMAS, Jürgen. Tecnologia e ciência como "ideologia". p. 52.

18 HABERMAS, Jürgen. Tecnologia e ciência como "ideologia". p. 51-52.

19 HABERMAS, Jürgen. Tecnologia e ciência como "ideologia". p. 78.

20 HABERMAS, Jürgen. A crise de legitimação no capitalismo tardio. p. 51-52.

21 HABERMAS, Jürgen. Tecnologia e ciência como "ideologia". p. 82. 
Conclui-se, então, que o contexto político atual viola a linguagem ou, especificamente, a forma da socialização e da individualização determinada pela comunicação mediante a linguagem comum, que é interesse inerente a uma das duas condições fundamentais da existência cultural humana. Segundo Jürgen Habermas, "este interesse entende-se tanto à manutenção de uma intersubjectividade da compreensão como ao estabelecimento de uma comunicação liberta da dominação"22. A dominação apolítica atual resulta no desaparecimento dessa característica por conta do interesse pela ampliação do poder de disposição técnica ${ }^{23}$.

Seus estudos culminaram no convencimento de que:

[...] a realidade com a qual confrontamos nossas proposições não é uma realidade nua, mas já, ela própria, impregnada de linguagem. A experiência, pela qual controlamos nossas suposições é linguisticamente estruturada e se encontra engastada nos contextos de ação ${ }^{24}$.

É essa trama pragmática que leva Jürgen Habermas a tecer a sua teoria democrática. Ressalta-se que o autor reconhece que seu modelo não é satisfatório, mas favorece a compreensão de teorias constitucionais orientadas por processos que perseguem um princípio crítico-reconstrutivo ${ }^{25}$.

\section{CONSTRUTOS INSTITUCIONAIS DA POLÍTICA PROCEDIMENTALISTA HABERMASIANA}

Por essas razões, antes de adentrar a explicação dos delineamentos da teoria democrática habermasiana, é essencial expor determinados conceitos-chave de tal construção científica - eis que se pretende evitar um truncamento de conceitos operacionais no decorrer deste capítulo, por conta da complexidade do tema.

Assim, são pressupostos das articulações argumentativas do referido: sociedade civil, esfera pública, mundo da vida, poder comunicativo e poder administrativo.

\section{a) Sociedade civil}

A sociedade civil ${ }^{26}$, em sua visão estrutura| ${ }^{27}$, é o conjunto de associações e organizações livres, não estatais e não econômicas, ancoradas em estruturas de comunicação da esfera pública. Segundo Jürgen Habermas:

[...] o núcleo da sociedade civil forma uma espécie de associação que institucionaliza os discursos capazes de solucionar problemas, transformando-os em questões de interesse geral no quadro de esferas públicas. Esses "designs" discursivos refletem, em suas formas de organização, abertas e igualitárias, certas características que compõem o tipo de comunicação em torno da qual se cristalizam, conferindo-Ihe continuidade e duração ${ }^{28}$.

22 HABERMAS, Jürgen. Tecnologia e ciência como "ideologia". p. 82.

23 HABERMAS, Jürgen. Tecnologia e ciência como "ideologia". p. 82.

24 HABERMAS, Jürgen. Verdade e justificação. São Paulo: Loyola, 2004. p. 45.

25 HABERMAS, Jürgen. Direito e moral. Lisboa: Piaget, 1992. p. 66-67. Ainda: "A qualidade racional da legislação política não depende, somente, do modo como as maiorias eleitas e as minorias protegidas actuam dentro do parlamento. Ela depende, igualmente, do nível dos participantes e da formação escolar, do grau de informação e do rigor de articulação, de questões resumidamente controversas: do carácter discursivo da formação da opinião, não institucionalizada, na esfera pública política. A qualidade da vida pública é, em geral, determinada pelas oportunidades reais, que revelem a esfera pública política com os seus meios e estruturas. Todos estes princípios expõem-se, na verdade, à dúvida em saber se a posição do problema não é já, desesperadamente ínfima, face a uma complexidade social em rápida progressão."

26 Para Jürgen Habermas, "essa esfera da sociedade burguesa foi redescoberta recentemente, porém em constelações históricas totalmente diferentes. O atual significado da expressão 'sociedade civil' não coincide com o da 'sociedade burguesa', da tradição liberal, que Hegel chegara a tematizar como 'sistema de necessidades', isto é, como sistema do trabalho social e do comércio de mercadoria numa economia de mercado. Hoje em dia, o termo 'sociedade civil' não inclui mais a economia constituída através do direito privado e dirigida através do trabalho, do capital e dos mercados de bens, como ainda acontecia na época de Marx e do marxismo." HABERMAS, Jürgen. Mudança estrutural da esfera pública. 2. ed. Rio de Janeiro: Tempo Brasileiro, 2003. p. 99.

27 Diferenciada da visão sistemática definida anteriormente.

28 HABERMAS, Jürgen. Mudança estrutural da esfera pública. p. 99. 
Assim, a sociedade civil compõe-se de movimentos, organizações e associações que emanam os problemas sociais das esferas privadas, de modo que os sintetizam e promovem a sua transmissão para a esfera pública.

\section{b) Esfera pública ${ }^{29}$}

A esfera pública não é entendida como uma instituição ou uma organização, já que não constitui uma estrutura normativa nem regula o modo que pertença a uma organização ${ }^{30}$. Ao contrário, a esfera pública é descrita "como uma rede adequada para a comunicação de conteúdos, tomadas de posição e opiniões", em que "os fluxos comunicacionais são filtrados e sintetizados, a ponto de se condensarem em opiniões públicas enfeixadas em temas específicos" 31 .

Nesse sentido, o autor analisa que:

[...] a esfera pública se reproduz através do agir comunicativo, implicando apenas o domínio de uma linguagem natural; ela está em sintonia com a compreensibilidade geral da prática comunicativa cotidiana. [...] Todavia, a esfera pública não se especializa em nenhuma destas direções; pois isso, quando abrange questões politicamente relevantes, ela deixa a cargo do sistema político a elaboração especializada ${ }^{32}$.

Assim, tem-se a esfera pública como uma estrutura de comunicação vinculada ao agir orientado pelo entendimento e ao espaço social gerado no agir comunicativo, explanado a seguir.

\section{c) Mundo da vida}

De importância fundamental à teoria democrática exposta, o mundo da vida corresponde a um conceito de mundo compartilhado, a partir do qual se pode inferir a existência de estruturas da racionalidade comunicativa, por via reconstrutiva ${ }^{33}$, em que se verifica:

[...] a pluralidade das formas e das histórias de vida contra a singularidade da história mundial e do mundo da vida, a alteridade dos jogos de linguagem e dos discursos contra a identidade da linguagem e dos diálogos, os contextos cambiantes contra os significados fixados equivocadamente ${ }^{34}$.

No mundo da vida, então,

[...] a unidade da razão não pode ser percebida a não ser na multiplicidade de suas vozes, como sendo uma possibilidade que se dá, em princípio, na forma de uma passagem ocasional, porém, compreensível, de uma linguagem para a outra. E esta possibilidade de entendimento, assegurada apenas de modo processual e realizada de modo transitório, forma o pano de fundo para a variedade daquilo com que nos defrontamos na atualidade, sem que possamos compreendê-lo ${ }^{35}$.

Diante disso, tem-se, como mundo da vida habermasiano, um contexto fenomenológico compartilhado intersubjetivamente e sempre presente para todos os atores, de forma linguística.

29 Expressa Jürgen Habermas que, "nas condições de sociedades modernas, a esfera pública política da comunidade democrática adquire um significado sintomático para a integração da sociedade. Porquanto as sociedades complexas só podem ser mantidas coesas normativamente por meio de uma solidariedade entre cidadãos, extremamente abstrata e mediada pelo direito. Entre cidadãos da sociedade que não podem mais conhecer-se pessoalmente, é possível criar e reproduzir uma comunhão fragmentária, através do processo de formação pública da opinião e da vontade. Já que é possível auscultar o estado de uma democracia sentindo as pulsações de sua esfera pública política." HABERMAS, Jürgen. Entre naturalismo e religião: estudos filosóficos. Rio de Janeiro: Tempo Brasileiro, 2007, p. 29.

30 HABERMAS, Jürgen. Mudança estrutural da esfera pública. p. 92.

31 HABERMAS, Jürgen. Mudança estrutural da esfera pública. p. 92.

32 HABERMAS, Jürgen. Mudança estrutural da esfera pública. p. 92. Ainda: "Descobrimos que o mundo da vida é um reservatório para interações simples; e os sistemas de ação e de saber especializados, que se formam no interior do mundo da vida, continuam vinculados a ele. Eles se ligam a funções gerais de reprodução do mundo da vida (como é o caso da religião, da escola e da família), ou a diferentes aspectos de validade do saber comunicado através da linguagem comum (como é o caso da ciência, da moral, da arte)".

33 ARAGÃo. Lucia. Habermas: filósofo e sociólogo do nosso tempo. Rio de Janeiro: Tempo Brasileiro, 2002. p. 116

34 HABERMAS, Jürgen. Pensamento pós-metafísico: estudos filosóficos. 2. ed. Rio de Janeiro: Tempo Brasileiro, 2002. p. 151.

35 HABERMAS, Jürgen. Mudança estrutural da esfera pública. p. 153. 
Sua estrutura dá-se por meio de tradições, instituições e identidades que são criadas a partir dos processos de socialização.

Essa definição, portanto, espelha todos os saberes que são utilizados como ponto de partida para as ações dos indivíduos, para tornar possível o entendimento entre eles. Sobre isso, Jürgen Habermas afirma:

[...] enquanto o falante e o ouvinte se entendem frontalmente acerca de algo no mundo, eles se movem dentro do horizonte do seu mundo de vida comum e este continua a ser, para os intervenientes, como um pano de fundo intuitivamente conhecido, não problemático, indesmembrável e holístico ${ }^{36}$.

Portanto se vê que o mundo da vida é um meio apreendido, estritamente vinculado às situações de fala e que pode ser modificado ou mantido a partir da comunicação estabelecida entre os sujeitos participantes de um debate.

\section{d) Poder comunicativo e poder administrativo}

O poder comunicativo é definido como uma estrutura autorreferencial da esfera pública, cuja tarefa "é se estabilizar a si mesma; a cada nova contribuição [...], o discurso público tem que manter presente o sentido de uma esfera pública política intacta"13. Assim, a esfera pública, por meio do poder comunicativo, tem a função de tematizar-se a si mesma.

O poder administrativo, por sua vez, representa a relação hierárquica do Estado com os sujeitos e consiste na substituição da violência que os indivíduos possuem em estado natural, pela violência organizada do estado civil, e que permite a constituição das instâncias do estado de direito, a legislação, o governo e a justiça como uma ordem legal e, por fim, estabelece faculdades e competências que autorizam o estado de direito a tomar decisões vinculantes ${ }^{38}$.

O poder administrativo é instrumental e deve ser programado pela formação democrática da opinião e da vontade. Assim, unindo-se ao poder comunicativo, forma o poder político, para que possa agir e executar em função da sociedade civili39.

Diante disso, torna-se possível a explanação acerca da teoria político-democrática habermasiana.

\section{TIPOLOGIA DEMOCRÁTICA EM JÜRGEN HABERMAS E A TEORIA DA DEMOCRACIA PROCEDIMENTALISTA OU POLÍTICA DELIBERATIVA}

Ante a violação do interesse inerente à espécie humana, que é a emancipação, partindo dos pressupostos de que a identidade do sistema político não mais deriva da sociedade e a sociedade não reconhece mais a dominação política em forma pessoal, Jürgen Habermas, após promover sua própria classificação das teorias democráticas vigentes e a diferenciação entre as concepções liberal e republicana, oferta a sua proposta de adequação das instituições estatais aos valores da sociedade civil.

36 HABERMAS, Jürgen. O discurso filosófico da modernidade. Lisboa: Dom Quixote, 1990. p. 278.

37 HABERMAS, Jürgen. Direito e democracia: entre facticidade e validade. v. II. Rio de Janeiro: Tempo Brasileiro, 2003. p. 272-273. Conceituação de poder comunicativo trazida de A. Wellmer, que, por sua vez, apoiou-se em $\mathrm{H}$. Arendt. "As instituições da liberdade pública têm o seu fundamento no solo movediço da comunicação política daqueles que, ao utilizá-la, a interpretam e defendem. Tal reprodução autorreferencial da esfera pública revela o lugar onde se refugiou a expectativa de uma auto-organização soberana da sociedade. A sequência disso é uma dessubstancialização da ideia de soberania do povo. No entanto, a própria ideia de que uma rede de associações poderia tomar o lugar do corpo popular, que foi rejeitado, é por demais concretista." HABERMAS, Jürgen. Direito e democracia: entre facticidade e validade. v. II. p. 272-273.

38 HABERMAS, Jürgen. A inclusão do outro: estudos de teoria política. São Paulo: Edições Loyola, 2002. p. 282.

39 HABERMAS, Jürgen. A inclusão do outro: estudos de teoria política. p. 282. 
Para Habermas, a concepção liberal do processo democrático é:

[...] a tarefa de programar o Estado para que se volte ao interesse da sociedade. Imagina-se o Estado como aparato da administração pública, e a sociedade como sistema de circulação de pessoas em particular e do trabalho social dessas pessoas, estruturada segundo leis de mercado ${ }^{40}$.

Por consequência, nessa concepção, a política, como formação da vontade dos cidadãos, tem uma finalidade mediadora: a reunião e a imposição de interesses particulares mediante o aparelho estatal, que se formou para o uso do poder para finalidades coletivas ${ }^{41}$.

\section{CONCEPÇÃO REPUBLICANA}

Segundo a concepção republicana, por outro lado, a política é uma forma de reflexão sobre um contexto de vida ético, diz o autor, e que permite que:

[...] os integrantes de comunidades solidárias se conscientizem de sua interdependência mútua e, como cidadãos, deem forma e prosseguimento às relações preexistentes de reconhecimento mútuo, transformando-as de forma voluntária e consciente em uma associação de jurisconsortes livres e iguais ${ }^{42}$.

Nesse raciocínio, Jürgen Habermas afirma que:

[...] ao lado da instância hierárquica reguladora do poder soberano estatal e da instância reguladora descentralizada do mercado, ou seja, ao lado do poder administrativo e dos interesses próprios, surge também a solidariedade como terceira fonte de integração social ${ }^{43}$.

Para tanto, o autor lembra que, para que seja possível a autodeterminação por parte dos cidadãos na esfera do Estado, é pressuposta:

[...] uma base social autônoma que independa da administração pública e da mobilidade socioeconômica privada, e que impeça a comunicação política de ser tragada pelo Estado e assimilada pela estrutura de mercado ${ }^{44}$.

Tal conjuntura só é possível quando o processo de formação da vontade e de opiniões políticas dá-se por meio do poder comunicativo, o que será tratado no capítulo seguinte.

\section{AS CONCEPÇÕES LIBERAL E REPUBLICANA E CONCEITUAÇÕES DO CIDADÃO DO ESTADO, DO DIREITO EM SI E DA NATUREZA DO PROCESSO POLÍTICO}

Dentre as diferenciações conceituais advindas dessa classificação habermasiana, destacam-se as diferenças entre a concepção de cidadão do Estado, do conceito de direito em si mesmo e o dissenso teórico referente à natureza do processo político.

Com relação à delimitação conceitual de cidadão do Estado, a concepção liberal determina o status de cidadão de acordo com os direitos individuais de que o sujeito dispõe em face do Estado e dos outros cidadãos. Esses direitos são subjetivos e representam direitos negativos que, segundo o autor:

[...] oferecem aos cidadãos a possibilidade de conferir validação a seus interesses particulares, de maneira que esses possam ser agregados a outros interesses privados (por meio de cotações, formação de corporações parlamentares e composições de governos) e afinal transformados em uma vontade política que exerça influência sobre a administração ${ }^{45}$.

40 HABERMAS, Jürgen. A inclusão do outro: estudos de teoria política. p. 270.

41 HABERMAS, Jürgen. A inclusão do outro: estudos de teoria política. p. 270.

42 HABERMAS, Jürgen. A inclusão do outro: estudos de teoria política. p. 270.

43 Grifo do autor. HABERMAS, Jürgen. A inclusão do outro: estudos de teoria política. p. 270.

44 HABERMAS, Jürgen. A inclusão do outro: estudos de teoria política. p. 270.

45 HABERMAS, Jürgen. A inclusão do outro: estudos de teoria política. p. 271. 
A concepção republicana, por sua vez, declara que os direitos dos cidadãos são positivos e garantem a participação em uma práxis comum dos "sujeitos politicamente responsáveis de uma comunidade de pessoas livres e iguais"46. Logo, o processo político não se constitui em mera função mediadora entre Estado e sociedade, mas surge "do poder gerado comunicativamente em meio à práxis de autodeterminação dos cidadãos do Estado e legitima-se pelo fato de defender essa mesma práxis através da institucionalização da liberdade pública"47.

Também é diverso o sentido da ordem jurídica, segundo discriminado por Jürgen Habermas. Na liberal, caracteriza a verificação de quais direitos individuais correspondem a um caso específico; na republicana, os direitos individuais encontram-se em uma ordem jurídica objetiva, que estabelece o convívio equitativo, autônomo e fundamentado sobre o respeito mútuo ${ }^{48}$.

Por fim, a política, para a concepção liberal, refere-se tão somente a uma luta por posições que permitam dispor do poder administrativo, cujos agentes agem estrategicamente para a conquista ou para a manutenção do poder - concorrência esta que determina o processo de formação da vontade e da opinião política. Na concepção republicana, ao contrário:

[...] a formação de opinião e vontade política em meio à opinião pública e no parlamento não obedece às estruturas de processos de mercado, mas às renitentes estruturas de uma comunicação pública orientada ao entendimento mútuo ${ }^{49}$.

Elucida Jürgen Habermas que:

[...] o embate de opiniões ocorrido na arena política tem força legitimadora não apenas no sentido de uma autorização para que se ocupem posições de poder; mais que isso, o discurso político ocorrido continuamente também apresenta força vinculativa diante desse tipo de exercício de dominação política ${ }^{50}$.

Como corolário, a concepção liberal defende que a formação democrática da vontade tem exclusivamente a função de legitimar o exercício do poder político, enquanto que a concepção republicana sustenta que a formação democrática da vontade tem a função, essencialmente mais forte, de constituir a sociedade como uma coletividade política e de manter viva, a cada eleição, a lembrança desse ato fundador ${ }^{51}$.

Frente a tal embate, Jürgen Habermas propõe a concepção procedimentalista ou política deliberativa, colhendo elementos da concepção liberal e da concepção republicana.

\section{CONCEPÇÃO PROCEDIMENTAL HABERMASIANA}

Integrando as concepções transcritas anteriormente em um conceito que o autor considera como um procedimento ideal para o aconselhamento e a tomada de decisões ${ }^{52}$, Jürgen Habermas propõe um procedimento democrático que:

[...] cria uma coesão interna entre negociações, discursos de autoentendimento e discursos sobre a justiça, além de fundamentar a suposição de que sob tais condições se almejam resultados ora racionais, ora justos e honestos ${ }^{53}$.

Assim, em contraponto à interpretação liberal (em que a formação democrática da vontade tem como função única a legitimação do exercício do poder político) e à interpretação republicana (cuja formação democrática tem uma função muito mais importante, que é a de constituir a sociedade como uma comunidade política e manter viva, em cada eleição, a recordação desse ato fundador), observa-se outro pensamento na teoria deliberativa habermasiana:

46 HABERMAS, Jürgen. A inclusão do outro: estudos de teoria política. p. 272.

47 HABERMAS, Jürgen. A inclusão do outro: estudos de teoria política. p. 272.

48 HABERMAS, Jürgen. A inclusão do outro: estudos de teoria política. p. 273.

49 HABERMAS, Jürgen. A inclusão do outro: estudos de teoria política. p. 275.

50 HABERMAS, Jürgen. A inclusão do outro: estudos de teoria política. p. 275-276.

51 HABERMAS, Jürgen. A inclusão do outro: estudos de teoria política. p. 281.

52 HABERMAS, Jürgen. A inclusão do outro: estudos de teoria política. p. 278.

53 HABERMAS, Jürgen. A inclusão do outro: estudos de teoria política. p. 278. 
[...] processos e pressupostos comunicativos de formação democrática da opinião e da vontade funcionam como a comporta mais importante para a racionalização discursiva das decisões de um governo e de uma administração vinculados ao direito e à lei. [...] O poder disponível administrativamente modifica sua composição durante o tempo em que fica ligado a uma formação democrática de opinião e da vontade, a qual programa, de certa forma, o exercício do poder político ${ }^{54}$.

A ideia de soberania popular, portanto, em seu prisma procedimentalista, atenta para condições sociais periféricas, "que possibilitam a auto-organização de uma comunidade jurídica sem, no entanto, encontrar-se simplesmente à mercê da vontade dos cidadãos"

Para tanto, faz-se necessário que exista uma autocompreensão normativa da política deliberativa, a fim de que seja possível a promoção de um modo discursivo de socialização da comunidade, o que favorece o exame das questões públicas sob a ótica ética, política e moral.

O processo democrático procedimentalista é obtido tendo como base a ideia de que o consenso é o telos da linguagem, e que o sucesso da comunicação depende de o destinatário da mensagem incorporar o ponto de vista do seu emitente. Assim, o discurso, na democracia habermasiana, defende a necessidade da relação intersubjetiva para a realização dos processos de entendimento mútuo, configurados na instituição de aconselhamento, em corporações parlamentares e na rede comunicativa formada pela opinião pública de cunho político.

Desse modo, a política deliberativa possibilita uma relação interna entre os contextos de universo de vida cooperativo e racionalizado, eis que se desenvolve em conformidade com os procedimentos convencionais da formação institucionalizada da opinião e da vontade, ou de modo informal, nas redes de opinião pública ${ }^{56}$.

Com isso, a legitimidade das decisões e das instituições democráticas, segundo a concepção procedimentalista de Jürgen Habermas, somente será alcançada se o aparato estatal for elaborado a partir de processos comunicativos livres de coação do aparato administrativo estatal e dos sistemas econômicos e com fundamento na teoria discursiva habermasiana.

\section{CONSIDERAÇÕES FINAIS}

Revendo-se os discursos políticos e jurídicos mais variados, impostos sedimentação de uma configuração sociopolítica de conveniência, verifica-se que a sua base de justificação fortalece-se, sobremaneira, com a aceitação dos sujeitos atingidos com os efeitos do referido discurso. Obtém-se, assim, o consenso entre os participantes de um dado mundo da vida; por consequência, tem-se a verdade compartilhada de determinado grupo social, ratificando a forma com a qual é conduzida a cosia pública.

Essa noção pragmática da democracia foi decisiva para Jürgen Habermas na elaboração da política procedimentalista. Ciente das carências do termo, o marco teórico aqui estudado pautouse não no conteúdo da forma política da democracia, mas sim em sua estrutura, o que explica a nomenclatura de sua teoria.

$\mathrm{Na}$ configuração de seu modelo político, Jürgen Habermas, utilizando metaconceitos que ele próprio elaborara e englobara em seu sistema teórico, construiu uma hipótese democrática baseada na formação discursiva de opinião e de vontade. Isso se deve ao fato de que, segundo seus ensinamentos, há, inicialmente, a configuração de um núcleo social e somente após se observa a configuração de um Estado e de um Direito, os quais devem guarnecer a convivência social. Nessa sequência, a democracia, antes de tudo, revela-se em um formato de socialização e convivência, em que se define, especialmente, qual a movimentação e o exercício do poder político dentro da sociedade, a partir do mundo da vida compartilhado formado por seus membros, que fornecem, consciente ou levianamente, os valores-guia do convívio entre eles.

O mundo da vida compartilhado, ou objetivo, conforme explanado, é edificado pelas tradições, instituições e identidades, criadas a partir dos processos de socialização, e define um contexto

54 HABERMAS, Jürgen. A inclusão do outro: estudos de teoria política. p. 23.

55 HABERMAS, Jürgen. A inclusão do outro: estudos de teoria política. p. 25.

56 HABERMAS, Jürgen. A inclusão do outro: estudos de teoria política. p. 284. 
fenomenológico vivido intersubjetivamente pelos sujeitos. E é no convívio entre os indivíduos pertencentes a um mesmo grupo social que se faz possível, considerando que todos os participantes são titulares e capazes de juízos de valor, o autoentendimento e, por conseguinte, a formação estrutural de um Estado que, por intermédio do Direito, satisfaça os interesses da sociedade ditados pelo consenso havido entre seus membros.

Nesses termos, os processos comunicativos de formação democrática da opinião e da vontade representam a origem e a chancela para a racionalização discursiva das decisões de um governo e de uma administração vinculados ao Direito. $E$ isso é feito a partir do poder comunicativo existente na sociedade civil, o qual define os valores existentes no bojo social, unido ao poder administrativo, poder instrumental titularizado pelo Estado.

Deste modo, portanto, faz-se possível a tutela juridicamente dos bens valorizados pela sociedade civil, a qual, a partir do poder comunicativo, influencia o poder administrativo e gera o poder político, que, por seu turno, deve proporcionar, por meio de políticas públicas e legislativas, condições sociais, técnicas e ecológicas de vida que guarneçam o que é valorizado convencionalmente e que mantenham a imprescindível comunicação entre os membros do grupo social - isso porque é nesse ponto que se sedia a legitimidade das instituições estatais: o poder comunicativo, gerado a partir do consenso social, proporciona a gênese legitimista às formatações do Estado e do Direito.

\section{REFERÊNCIAS}

ARAGÃO. Lucia. Habermas: filósofo e sociólogo do nosso tempo. Rio de Janeiro: Tempo Brasileiro, 2002.

BORGES, Bento Itamar; GOMES, Luiz Roberto; JESUS, Osvaldo Freitas (Org.). Direito e democracia em Habermas: pressupostos e temas em debate. São Paulo: Xamã, 2010.

HABERMAS, Jürgen. A crise de legitimação no capitalismo tardio. 2. ed. Rio de Janeiro: Edições Tempo Brasileiro, 2002.

A inclusão do outro: estudos de teoria política. São Paulo: Edições Loyola, 2002.

. Direito e moral. Lisboa: Piaget, 1992.

. Entre naturalismo e religião: estudos filosóficos. Rio de Janeiro: Tempo Brasileiro, 2007.

Mudança estrutural da esfera pública. 2. ed. Rio de Janeiro: Tempo Brasileiro, 2003.

O discurso filosófico da modernidade. Lisboa: Dom Quixote, 1990.

. Direito e democracia: entre facticidade e validade. v. II. Rio de Janeiro: Tempo Brasileiro, 2003.

2002.

Pensamento pós-metafísico: estudos filosóficos. 2. ed. Rio de Janeiro: Tempo Brasileiro,

Tecnologia e ciência como "ideologia". Lisboa: Edições 70, 2009.

Verdade e justificação. São Paulo: Loyola, 2004. 